\title{
Crohn's disease: We are in it for the long haul
}

\author{
Remo Panaccione MD¹, Paul C Adams MD FRCPC ${ }^{2}$, Editor-in-Chief
}

$\mathrm{D}_{\mathrm{N}}^{\mathrm{r}}$ Panaccione is currently an Associate Professor of Medicine at the University of Calgary (Calgary, Alberta). He is also Director of the Inflammatory Bowel Disease Clinic, and Director of the Postgraduate Gastroenterology Training Program at the University of Calgary. Dr Panaccione completed advanced training in Inflammatory Bowel Disease at the Mayo Clinic in Rochester, Minnesota (USA). He joined the Faculty of Medicine at the University of Calgary in 1999.

PA: Can you outline the history of how we developed the idea that maintenance therapy was recommended for ulcerative colitis (UC) and not for Crohn's disease (CD)?

RP: In my opinion, much of what we believe regarding maintenance therapy in $\mathrm{UC}$ and $\mathrm{CD}$ was shaped by what drugs were traditionally available for UC and CD, and by what natural history studies have taught us.

In the case of UC, natural history studies have demonstrated that in individuals with disease beyond the rectum, approximately $75 \%$ to $80 \%$ will flare within one year if they are taken off chronic maintenance therapy (1-3). This, combined with the fact that sulfasalazine and newer mesalamine products are useful for maintenance of remission, the newer preparations are well tolerated, and there is a large safety window with this class, made it easy for the practising gastroenterologist to adopt this strategy.

In contrast, one can see CD patients go into remission for long periods of time when taken off their medication $(4,5)$. Although mesalamine

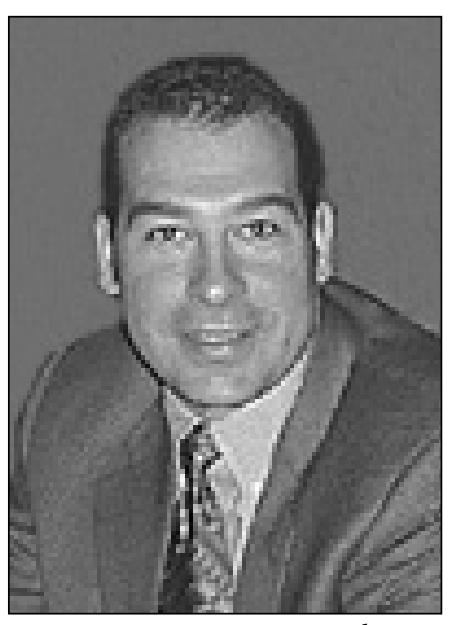

Dr Panaccione is currently an Associate Professor of Medicine at the University of Calgary (Calgary, Alberta). He is also Director of the Inflammatory Bowel Disease Clinic, and Director of the Postgraduate Gastroenterology Training Program at the University of Calgary. Dr Panaccione completed advanced training in Inflammatory Bowel Disease at the Mayo Clinic in Rochester, Minnesota (USA). He joined the Faculty of Medicine at the University of Calgary in 1999 products are not very beneficial to those who require maintenance therapy, they are used extensively in the community. Therefore, a physician is left with prescribing immunomodulating (IMM) agents such as the purine antimetabolites (6), methotrexate (7) or biologics. I believe that clinicians have been uncomfortable with the longterm use of these agents. That being said, I believe that gastroenterologists are becoming increasingly accustomed to the long-term use of nonbiologic immunosuppressants. The next hurdle is how comfortable they will be with the long-term use of biological agents such as infliximab and adalimumab.

PA: What has changed that may lead us to modify our recommendations for maintenance therapy for CD?

RP: The two natural history studies from Copenhagen county (Denmark) and Olmsted county (Minnesota) shed some important light on the fate of patients who require steroids to induce remission $(8,9)$. Both of these studies demonstrated that approximately one-half to two-thirds of patients will fail (defined as steroid-refractory or steroid-dependent) at one year. These patients will require a maintenance strategy. More sobering is that one-third of patients in the Olmsted county series required surgery within the first year of being on steroids. This, in addition to the increasing comfort level with the use of IMM agents, has changed maintenance practice in CD.

PA: Are we treating clinical symptoms, or inflamed mucosa at endoscopy?

RP: Traditionally, we have treated clinical symptoms. If the patient reported an improvement in symptoms, both the patient and his gastroenterologist were happy. In particular, in $\mathrm{CD}$, the traditional teaching was that there was a poor correlation between symptomatic improvement and mucosal healing. Much of this dogma came from the results of the Groupe d'Etude Thérapeutique des Affections Inflammatoires du Tube Digestives (GETAID) studies, which showed response rates of $90 \%$ with $1 \mathrm{mg} / \mathrm{kg}$ of prednisolone, but unimpressive endoscopic healing rates in the endoscopic substudy, with only 29\% of patients having endoscopic improvement and 9\% having a worsening of their endoscopic score (10).

However, in the era of biological therapy, we have seen a better correlation between symptomatic improvement and mucosal healing $(11,12)$. It makes intuitive sense that the goal should be to heal the end organ, not only to improve symptoms. It is my belief that many of the complications that lead to surgery, such as fibrostenosis or fistula, arise from poorly controlled disease at the mucosal level. If we can achieve improvement in clinical symptoms and improvement at the level of the mucosa, I believe that the patient will be better off in the long run. However, this needs to be demonstrated prospectively.

PA: Is there a dose of corticosteroids that is safe as a long-term maintenance therapy?

RP: This is a bit of a loaded question. The upfront answer is no. The goal of therapy is to induce and maintain remission in a steroid-free environment. If this is not being achieved, then we need to explore the reason for the ongoing need for steroids. This would include disease-related issues, in which case, the

\footnotetext{
${ }^{1}$ Division of Gastroenterology, Foothills Hospital, University of Calgary, Calgary, Alberta; ${ }^{2}$ Department of Medicine, University Hospital, London, Ontario

Correspondence: Dr Remo Panaccione, Division of Gastroenterology, TRW Building, 328 Hospital Drive Northwest, Calgary, Alberta

T2N 4N1. Telephone 403-592-5025, fax 403-592-5050, e-mail rpanacci@ucalgary.ca

Received and accepted for publication Janury 31, 2008
} 
strategy would be to 'escalate' or 'optimize' maintenance and steroid-sparing strategies; metabolic or endocrine issues in which adrenal insufficiency should be documented; and psychological dependency.

PA: What is the end point of therapies in CD?

RP: In 2008, the therapeutic end point is symptomatic remission when taken off steroids. This brings up the following question: "What is remission?" Remission in clinical trials is strictly defined by the $\mathrm{CD}$ activity index. In clinical practice, aiming to return the patient to their normal bowel function is ideal, realizing that this may not be attainable in all patients.

In 2008 and beyond, I predict that we will ask more, and there will be a push to normalize laboratory parameters and a patient's endoscopic or radiographic appearance. These are lofty goals, but we need to be up to the challenge for the good of our patients over the long term.

PA: Surgery is often seen as a failure in CD. Is surgery preferable to lifelong therapy with drugs, which are associated with high costs and potential toxicities?

RP: Surgery is not a failure in CD. It may be an undesirable outcome, but there are times when surgery is the right strategy. Examples include patients with limited terminal ileal disease with no previous surgeries, and patients with documented symptomatic strictures. Surgery for medically refractory disease is becoming less common as newer agents are introduced. The patients should be given medical and surgical options when they exist. However, in patients with a large burden of disease or in those who have had previous surgery, we should strive to optimize medical therapy.

PA: Can you predict our future approach for maintenance therapy in CD?

RP: I predict that an increasing number of patients will be on maintenance IMM agents or biological therapy. There has been much discussion and debate about the step-up versus top-down approach. I am not sure whether practising gastroenterologists are ready for top-down when it comes to induction and maintenance. I prefer what I refer to as the accelerated step-up or timebound approach, in which patients are evaluated regarding their response to medications at certain time points based on what is expected for that drug. If they are not responding optimally, then new therapies should be introduced.

\section{REFERENCES}

1. Langholz E, Munkholm P, Davidsen M, Binder V. Course of ulcerative colitis: Analysis of changes in disease activity over years. Gastroenterology 1994;107:3-11.

2. Hendriksen C, Kreiner S, Binder V. Long term prognosis in ulcerative colitis - based on results from a regional patient group from the county of Copenhagen. Gut 1985;26:158-63.

3. Henriksen M, Jahnsen J, Lygren I, et al; IBSEN Study Group. Ulcerative colitis and clinical course: Results of a 5-year population-based follow-up study (the IBSEN study). Inflamm Bowel Dis 2006;12:543-50.

4. Munkholm P, Langholz E, Davidsen M, Binder V. Disease activity courses in a regional cohort of Crohn's disease patients. Scand J Gastroenterol 1995;30:699-706.

5. Silverstein MD, Loftus EV, Sandborn WJ, et al. Clinical course and costs of care for Crohn's disease: Markov model analysis of a population-based cohort. Gastroenterology 1999;117:49-57.

6. Pearson DC, May GR, Fick G, Sutherland LR. Azathioprine for maintaining remission of Crohn's disease. Cochrane Database Syst Rev 2000:CD000067.

7. Feagan BG, Fedorak RN, Irvine EJ, et al. A comparison of methotrexate with placebo for the maintenance of remission in Crohn's disease. North American Crohn's Study Group Investigators. N Engl J Med 2000;342:1627-32.

8. Munkholm P, Langholz E, Davidsen M, Binder V. Frequency of glucocorticoid resistance and dependency in Crohn's disease. Gut 1994;35:360-2.

9. Faubion WA Jr, Loftus EV Jr, Harmsen WS, Zinsmeister AR, Sandborn WJ. The natural history of corticosteroid therapy for inflammatory bowel disease: A population-based study. Gastroenterology 2001;121:255-60.

10. Modigliani R, Mary JY, Simon JF, et al. Clinical, biological, and endoscopic picture of attacks of Crohn's disease. Evolution on prednisolone. Groupe d'Etude Thérapeutique des Affections Inflammatoires Digestives. Gastroenterology 1990;98:811-8.

11. D'haens G, Van Deventer S, Van Hogezand R, et al. Endoscopic and histological healing with infliximab anti-tumor necrosis factor antibodies in Crohn's disease: A European multicenter trial. Gastroenterology 1999;116:1029-34.

12. Rutgeerts P, Diamond RH, Bala M, et al. Scheduled maintenance treatment with infliximab is superior to episodic treatment for the healing of mucosal ulceration associated with Crohn's disease. Gastrointest Endosc 2006;63:433-42. 


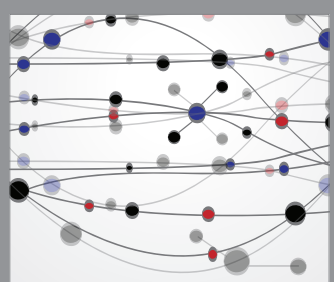

The Scientific World Journal
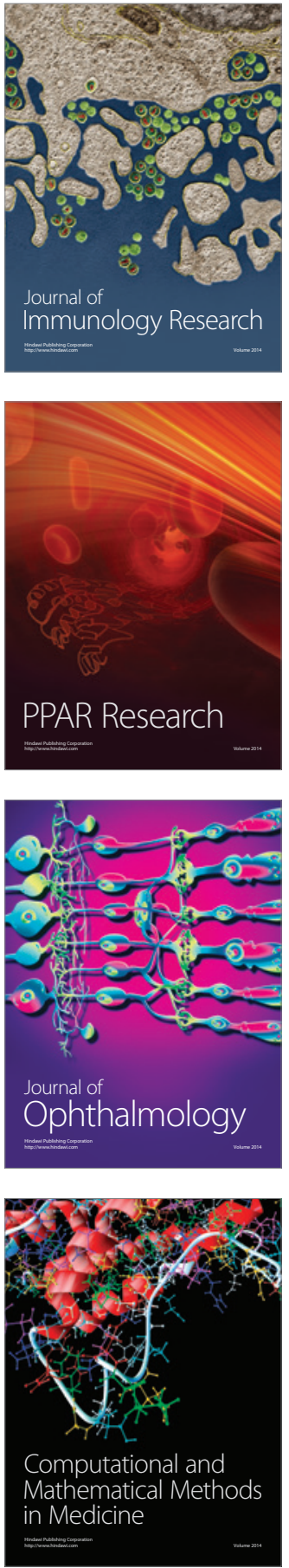

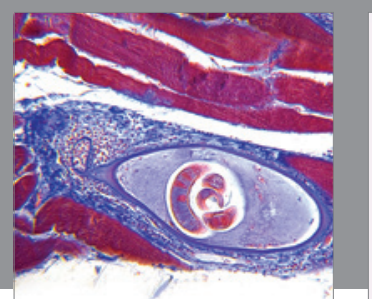

Gastroenterology Research and Practice

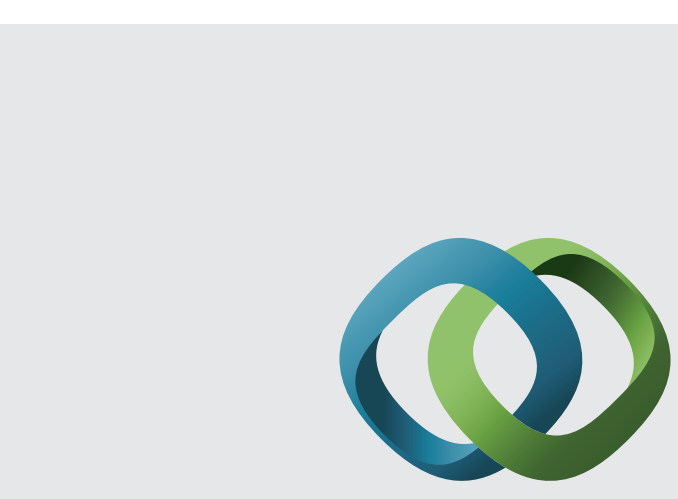

\section{Hindawi}

Submit your manuscripts at

http://www.hindawi.com
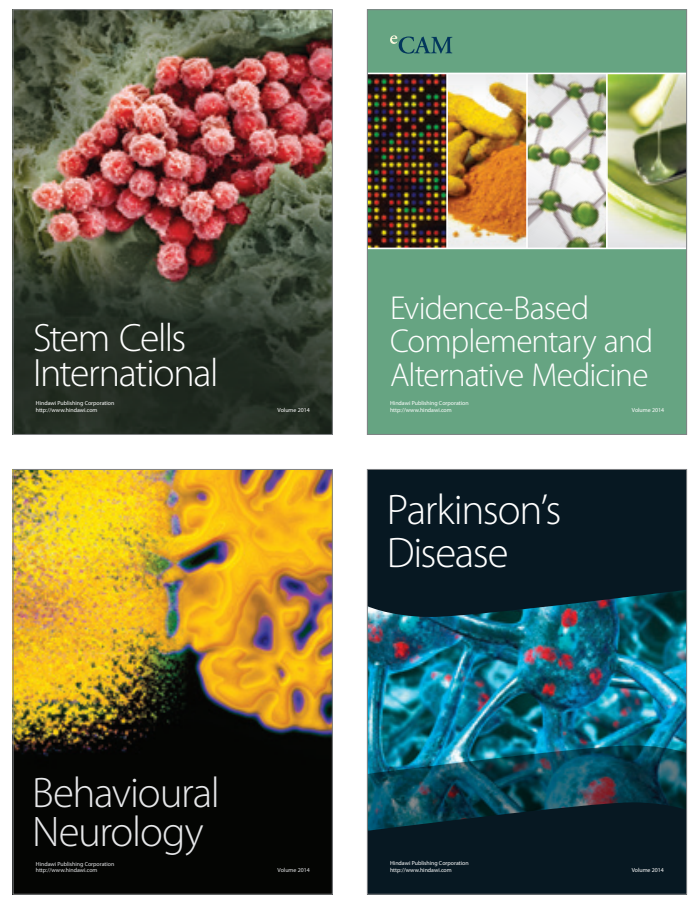
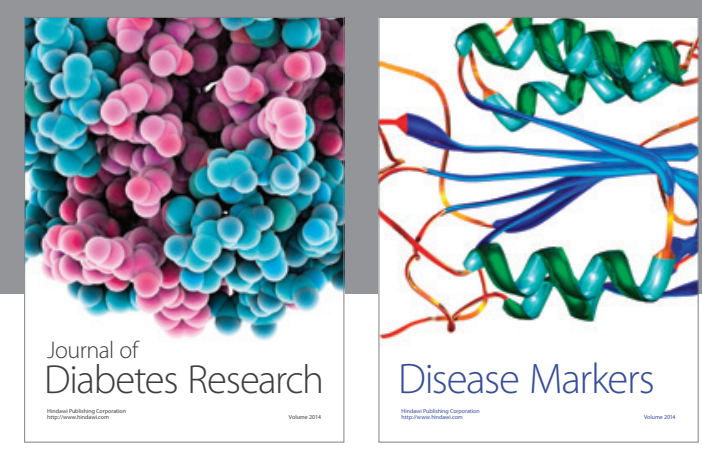

Disease Markers
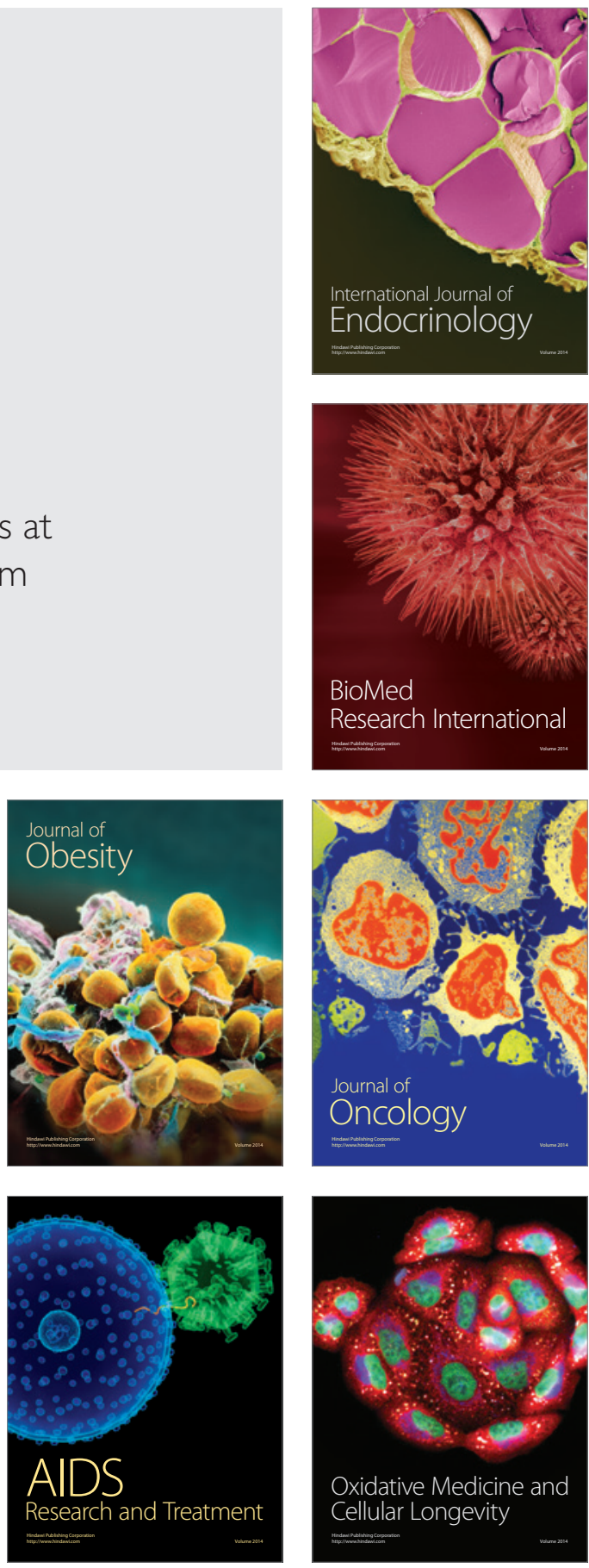